\title{
Challenges in Providing Information and Communication Technology (ICT) Education in Aboriginal Canadian Schools
}

\author{
Lorraine Frost $^{1}$, Katarin MacLeod ${ }^{2}$, Gerald Laronde ${ }^{1}$ \\ ${ }^{1}$ Nipissing University, Canada \\ ${ }^{2}$ St. Francis Xavier University, Canada
}

\begin{abstract}
A case study approach was taken in examining Information and Communication Technology (ICT) education in schools among four geographically and culturally different Aboriginal communities located in Canada. The schools selected for the study were all operated by local Aboriginal Education Authorities. Quantitative and qualitative data were gathered using interviews, focus groups, and online surveys. Participants in the study were students in middle and high school, their teachers, and school administrators. Online surveys were followed by interviews and focus groups. ICT use in the classroom was examined as well as the challenges and benefits. There were different types of challenges among the schools. For three of the four communities, access to Internet was poor, even in one community that was close to a mid-sized Canadian city where high speed internet is available. All communities experienced challenges with providing current, well maintained computers to their students. Three of the schools lacked supportive infrastructure for their computers, lacking technicians and replacement machines. Teacher use of ICT in teaching varied as some teachers had had access to instruction in their professional preparation programs and others had not. Further, access to professional development for teachers was limited. Schools were challenged in purchasing software with limited budgets. Lack of software in Aboriginal languages was a problem unique to these schools.
\end{abstract}

\section{Introduction}

A case study approach was used in examining Information and Communication Technology (ICT) education in schools among four geographically and culturally different Aboriginal communities located in Canada. The schools were from communities of Ojibway, Algonquin, Inuit, and Haudenosaunee (Iroquois) people, located in Ontario, Quebec and Nunavut. One of the communities was an isolated fly in community, while the other three could be considered rural with varying drivable distances from a larger mainstream community. The

communities varied in size and ranged from a population of about 400 people to one of a few thousand people (exact numbers cannot be provided in order to avoid identifying the communities). The students, teachers, and administrators participated by responding to online surveys for which items were developed using the International Standards for Technology in Education (ISTE). The surveys were followed by individual interviews for teachers and administrators and group interviews for the students. The use of ICT in the classroom was examined as well as identification of the challenges and benefits. This paper will focus on the results of the interviews.

\section{Literature Review}

Secondary and post-secondary completion rates among Aboriginal persons in Canada are considerably lower than those found in the general population, especially for those Aboriginal persons who live in more northern and remote communities. Increasingly, strong digital literacy and fluency is needed to be successful in the workplace and the classroom and, therefore, it is essential that Aboriginal Canadians develop these skills in order to enjoy the same benefits of education and employment as do other Canadians. Laronde, MacLeod, and Frost [13] note that research to date has focused on the adoption of new technologies, the efficacy of laptops in education especially when used $1: 1$, professional preparation of teachers for the use of ICT, and identifying barriers to ICT integration into the classroom. Research on ubiquitous laptop programs in schools in Aboriginal communities, however, virtually does not exist [6]. Laronde, MacLeod, and Frost [13], in reviewing the available literature, found that ubiquitous laptop programs are one of the most effective means of achieving fluency in ICT, yet many schools lack the infrastructure and personnel to support such programs. The purpose of the research was to examine the extent to which ubiquitous laptop programs were being used effectively in selected Aboriginal communities.

Previous research conducted in 31 countries by the European Commission has found wide variance in use of ICT in members' schools [3]. Previous 
meta-analyses completed in areas of ubiquitous computing in schools include studies in student achievement [5], measurement of student writing [6], mathematics [12]; [14], and pre-service teacher education [11].

This research contributes to the literature on ICT use in schools and the literature on Aboriginal education. The term "Aboriginal" lumps all indigenous people of North America together, yet there are distinct cultures and languages within this large group, with further differences defined by geography and proximity to larger populated areas. The case studies reported in this paper were conducted in four different regions of Canada, representing four different cultural and language groups.

\section{Methodology}

Case study methodology was chosen as it "facilitates exploration of a phenomenon within its context using a variety of data sources". [1] A case study approach also recognized the uniqueness of the communities defined through their geography and culture. Thus the study reported herein is a multiple, descriptive case study. [1] Online surveys, interviews, and focus groups were used to collect data, resulting in a mixed methods study. [2] The schools were chosen as a convenience sample from communities of Ojibway, Algonquin, Inuit, and Haudenosaunee (Iroquois) people, located in Ontario, Quebec and Nunavut.

The schools were initially approached by the researchers through contact with the Administrator of the school to determine if ICT was being used in the school and if there was a willingness to participate in the study. In obtaining ethical approval at the university and community level, consideration was given to sensitivity in working with Aboriginal people, as well as young students.

Data gathering consisted of online surveys with students, teachers, and administrators using Fluidsurveys.com. The online survey link was sent to a Gmail address created by the researchers then given to and opened by the participants. This Gmail address was specifically created to maintain anonymity among the participants. It took approximately an hour of class time for the students to complete the online survey and participate in the focus group interview. Individual interviews with teachers and administrators were completed in private within a room in the school. All of the students' parents or guardians signed letters of consent prior to completion of the surveys and interviews. All participants signed letters of consent for the interviews and acknowledged consent in participating in the online survey. The interviews were recorded and transcribed at a later date. A follow up visit to the school for classroom observation was conducted for triangulation. Notes were taken throughout the data gathering process. Some data analysis of the online surveys was conducted with tools from Fluidsurveys.com. Some sample sizes, however, were too small for statistical analysis.

The online survey questions were loosely derived from the Survey of Schools: ICT in Education used in the European Commission and carried out by European Schoolnet [3]. In the interests of time and cultural appropriateness, the European Schoolnet survey instrument utilized was shortened and made more relevant to Aboriginal Canadians. The ISTE Essential conditions [10] were also used in the construction of the survey instrument and analysis of the data.

\section{Results}

\subsection{Ojibway First Nation}

The Ojibway First Nation high school was located in Northern Ontario in a community of approximately 1000 people. Note: the term "First Nation" refers to a community of Indigenous or Aboriginal people, recognized by the Government of Canada. The First Nations are usually located on the traditional territories of the community members. For more information on Canada's First Peoples, see Indigenous and Northern Affairs (2016). [9] The Internet connection was high speed, with password protected wifi being used throughout the school. The students and staff reported being satisfied with the speed and reliability of the Internet connection in the school. In the previous school year, there were problems with the system crashing as it was public and the high volume of use was not sustainable. Students were using their personal devices at school and that, coupled with the school computers, slowed down the system or made it unusable. Social media sites were blocked on the school system, a measure that was not popular with the students. They related that they would try to find ways to "hack into the system", sharing ideas with each other, so they could access social media. At the time of our visit, students had to use their personal data plans in order to check social media or for other use not permitted on the school computers. The teacher and administrator indicated that they were much happier with the speed of the Internet since making the changes. The administrator was at this time in the process of creating a proposal for funding for more bandwidth.

The students had iPads and MacBooks that were stored in the school on a charging cart. The laptops and iPads were used on a daily basis. The students named a number of benefits for the use of the laptops and iPads. They all included easier access to research through the Internet as one of the benefits. The teacher interviewed indicated that she appreciated the access to resources for research, both for the students and for her. The students appreciated the 
speed with which they could locate information, unlike, "the old days where you had to read through stacks and stacks of books." They mentioned that accessing the Internet raised the possibility of teaching themselves things. One student did caution that not all information found on the Internet was correct, showing a sophisticated understanding of the perils in trusting everything found online.

Another benefit mentioned by the students was that the use of computers facilitated organization through the use of Google drive. Students indicated that they liked being able to see their teachers' presentations in class on Google drive, and then being able to view those presentations again at home. They liked being able to submit their assignments through Google drive. One student who was a member of the student council mentioned that being able to organize messages and information in Outlook was an advantage. The teacher agreed that the students were much more organized this year and she felt that the use of Google drive had helped in this regard.

The students liked to use their computers for social media. As mentioned above, in order to keep the system from being overloaded, the school had placed a password on the wifi and had blocked social media. The students missed social media but seemed to have accepted that they should not be checking messages during the school day. When asked what their favourite programs were, students mainly mentioned social media platforms, streaming services, and live communications programs.

Another advantage mentioned by the students was that they found word processing to be more efficient than hand writing their assignments. They indicated that they could produce more work and that the work was of better quality. One student said his hand used to get sore from writing and he would stop. He said that his fingers did not become fatigued when he word processed his assignments.

The students recognized that computers could help with focus and also be distracting. They realized that unauthorized use, such as checking social media could make it difficult for them to complete their work in a timely fashion. On the other hand, they said that the computers could help with focus. When they were able to work efficiently, find the information that they needed, they thought the computers were motivating.

Students indicated that they used computers for live communication, specifically mentioning Skype and Google Hangout. The students shared that their school had made contact with a school in Guatemala and was trying to arrange for the students at the Ojibway High School to speak through Skype with the students in Guatemala. They mentioned that Google Hangout was useful for communicating with each other. The Student Council member reported that the council had met through Google Hangout at times.
Other advantages mentioned by individual students included: finding and making online purchases, doing genealogy research, keeping a schedule, and providing entertainment. They stated that they would like to have thinner, smaller machines to use and they wanted voice-to-text programs.

Challenges indicated by the staff were similar to those found in mainstream schools with concerns about technical problems, off task behavior among the students, and improper referencing, i.e. students copying material directly from the internet into assignments. The teacher and administrator identified barriers preventing the increased use of ICT, including the lack of professional development, resources, and Aboriginal language software. (Note: Aboriginal languages are under extreme pressure, especially languages once spoken in what are now the southern regions of Canada. Only $17 \%$ of Aboriginal people in Canada can converse at all in their language, and only $8.5 \%$ use it "most often" at home. Language recovery programs are being mounted in many Aboriginal communities in an effort to prevent their extinction). [4] [17]

The teacher who was interviewed taught a course in communications technology. She stated that the course focused on photography and digital imaging. This teacher taught history as well and has found that the capacity to teach the students research skills is enhanced by access to the computers. She was pleased that the students had a laptop to use in class as it was cumbersome to book the computer laboratory every time she wanted to use a program. Examples of programs that she mentioned using were Photoshop Elements, iMovie, and SketchUp. She mentioned that another teacher in the school was making extensive use of Desire2Learn, an e-learning platform or course management system.

Challenges mentioned by the teacher were that some of the students were more proficient at using computers and others were not very familiar with them. Therefore, there were wide differences in both skills and comfort levels in the classes. Some students felt overwhelmed when they were asked to complete a number of consecutive tasks using their laptops. Another challenge mentioned was being vigilant for plagiarism. Some students were copying and pasting directly from the Internet. The teacher shared that she was trying to educate the students about the proper use of online resources but some of them did not see copying from these resources as the same as copying from books. A third challenge expressed was that power outages are difficult to deal with since so many of the school's resources are now online. The teacher was solving that problem by tethering her phone to her computer, but noted that not all teachers would know how to do that. In terms of professional development, the teacher believed that there were different needs among the teaching staff and the most effective way to provide for them 
would be to have different experiences for teachers, depending on their level of development with ICT use.

The educational assistant at the school was interviewed. Her responsibilities included supporting students with special needs. She stated that the computers were advantageous for the non-verbal students with whom she worked. She stated that she was able to log onto the computer to see students' work and monitor what they were doing, rather than have to travel around to all the classrooms. She appreciated spell and grammar check features on the word processing programs for the students with special needs.

The administrator recognized there was a wide skill set range among teachers in the adoption of ICT integration into their teaching. She shared that some teachers were using SMARTBoards, but wanted to see this equipment used more fully in the school's classrooms. The administrator's recommendations included more professional development in ICT for teachers, additional resources for ICT, and more development of Aboriginal language software.

A benefit to the school, cited by the administrator, was the use of a program named Live Binders. Teachers in First Nations schools are posting their lesson plans and resources to be shared by other users of the program. The administrator stated that it was important that teachers have access to these materials, whether they were teaching in First Nations or not. She recognized the potential of this system to provide relevant curriculum materials.

The administrator related that she was trying to get agreement to record elders who were fluent in the indigenous language. She wanted to create a language resource that would be available for students. While the school does not have a Facebook page, the community does, and the administrator was trying to convince the cultural committee to put language instruction on the Facebook page for community members who wished to learn and practice the indigenous language.

This school had relatively good technical support, especially compared to the others schools, as discussed below. At first, the school contracted with a private IT business in the city that is near the community. When that business folded, the community arranged for services from a freelance technician. That technician installed the wifi system, but the school had many problems with it. They searched for a more competent technician and finally started using the services of another freelance technician. This technician charges $\$ 200$ per hour, but he fixed the problems left by the earlier technician and was upgrading and improving the system. The administrator seemed satisfied with the current technician's work. In addition to this technician, one of the teachers recently hired is knowledgeable about the use of ICT in schools and has been a great support in general.
Finally, the administrator spoke about the potential to use live communication systems, such as Skype, to offer low enrollment courses. She envisioned a system where students from two or more First Nations high schools could take courses that usually have low enrollments. The example she used was upper year science courses. By combining students from two or more schools via Skype, enrollment in the courses would be more robust and a greater variety of courses could be offered to all students. She commented that there are students in the high school who wish to pursue careers in the health sciences and they need the upper year science courses. Funding issues would have to be addressed, she said, as grants for schools are based on the local enrollment as a whole. At the time, there was no provision for course by course enrollment. It would require that enrollment be balanced among the participating schools in the courses being offered by this means. Another issue to be addressed for this program, and other shared programs, was that some of the participating communities used dial-up connections, which limited the possibilities quite considerably.

The administrator expressed a wish to find a balance between the use of technology and taking advantage of the environment around the school. She stated that some students spend a lot of time on their personal devices at home and she believed that they needed time away from computers.

In summary, this school solved earlier problems with Internet speed by introducing a password for the wifi and creating a firewall for social media and streaming programs, not a popular decision with the students. The school was able to acquire technical support through a freelance technician. One of the teachers on staff was quite knowledgeable about the use of ICT in education and was an informal resource for the school. The students, in general, seemed quite knowledgeable about the use of ICT for their schoolwork, although as the teacher noted, there were some students who were experiencing difficulties. Providing professional development for teachers was challenging. The school administrator was exploring means by which to capitalize on communications technology to offer low enrollment courses and share resources with other First Nations schools. Improved efficiency and access to resources for research were appreciated by students and staff alike. Increased support for students with special needs was appreciated by the staff. This administrator was working towards a goal of having one laptop or iPad per student and was close to achieving that. She was also trying to get approval for funds to increase bandwidth. A lack of software in the Aboriginal language was specified as a major limitation. 


\subsection{Algonquin First Nation}

The Algonquin First Nation school was located in Quebec. The school had a high speed fiber optic connection with wifi being used throughout the school. A new school is to be built in this community in the next few years. The Director of Education expressed the hope that high speed fiber optic connections would be available in the new school so that good access to the internet would continue to be available for staff and students. He said that he was working with different organizations in order to ensure that the new school would have fiber optics and reliable Internet access. The administrator hoped that the new school to be built would help improve access to computer use and storage. Unlike some of the other schools we visited, the administration, school staff, and students were all satisfied with the speed and reliability of the Internet connections available.

The school had a class set of iPads that were not used on a regular basis. It was not clear why the iPads were not used more often, but the administrator stated it was more of an organizational issue, as well as some teachers needing professional development in teaching with ICT. The students said that the computers in the laboratory were old and slow. They did, however, comment that they used these computers on a daily basis. If they wanted to use the computers outside of class time, they could do so with a note of permission from their teacher. The Director of Education noted that the school had just purchased 16 computers to be used by students with identified special education needs. Further, a comprehensive software package designed for students with special needs had been ordered for the purpose of supporting these students. All classrooms in the school were recently equipped with SMARTBoards.

The Director of Education and the principal both suggested that providing technical assistance and professional development to the teachers was a challenge. The technical support service used by this community is located a long distance away in Quebec City. While this community does have road access, technicians do not travel to the community because of the distance. The administrators spoke positively of the technical advice and support that was provided to the school, but recognized its limitations without onsite visits.

In terms of professional development, the principal commented that there was one teacher on staff who was fairly skilled in the use of ICT for teaching and learning purposes. The school was informally relying on this teacher to help. The principal noted that he was encouraging teachers to pursue professional development in the use of ICT in their classrooms but that some teachers were resistant to changing the way they teach. He remarked that he was trying to provide as much support as he could to the teachers, but that his personal knowledge had limitations. The Director of Education expressed concern that equipment and software were being purchased for the school, but without adequate professional development for the teachers, it was not being used as effectively or extensively as possible. He stated that the money spent on these resources was hard to acquire and he wanted to ensure that maximum benefit was available for the students. Otherwise, he commented, the money was wasted and could have been used for something else.

One issue with professional development for teachers was related to the problem of teacher turnover. The director and principal conveyed that teachers from outside the community usually did not stay a long time in the school. Those teachers who were members of the community were likely to teach in the school for most of their careers. The director, while ensuring that all teachers had professional development, wanted to be certain that the local teachers continued to receive support in developing their skills, as a long term investment for the school. In fact, he remarked that he tended to focus on the local teachers for this reason. The teacher we interviewed for this research said that she had received good instruction in her teacher education program regarding the use of ICT for teaching and learning and was relying on that previous learning. She did not feel that she had progressed in her knowledge since commencing her position at the school.

This teacher, who was interviewed, related that she relied on computers to help the students with special needs with their writing and reading skills in her high school level classes. She commented that the school computer lab was heavily used and fully booked, and that she would like to have more access to computers for her students. She commented that she used the SMARTboard in her classroom on a regular basis. She found that the SMARTboard engaged students more effectively and that she could use video and demonstrations to enhance her lessons. When asked about programs or capacities she would like to have, she stated that she would like to have programs that would allow video production. She said the students had been using their personal phones to create and edit videos, which they have found very motivating. She said that she would like to have more software to use that would make her lessons more interactive. She indicated that she was not aware of any software that was in the Algonquin language (other than the language software, mentioned below).

When we asked the Director of Education about support for teaching and learning the indigenous language, he told us that the school was using software that was designed to teach the Algonquin language. The program that they were using allowed the students to type in words or phrases and the 
program would voice the translation in Algonquin. Essentially, the program translates from English to Algonquin. The pedagogical limitations for teaching a language with this type of software are obvious and will not be discussed here. This program, however, seemed to be the only one that the school had found in the Algonquin language and so it was being used to support the teaching of the indigenous language. The Director expressed concern that the Algonquin dialect in the software, while close to the dialect spoken in the community, was different. The students echoed the same concern by saying the dialect was "too different" and that the dialects were "too different for all communities", making production of Algonquin language software challenging. The students were asked if they used the software during their language classes to complete their assignments. They disclosed that they did use it, but infrequently. Only one student in the focus group stated that he spoke Algonquin at home. The Director explained that the tribal council very much wanted software that would support the teaching of the Algonquin language in its territory schools.

When the students were asked in the focus group which programs were their favourites, they mainly named social media programs and search engines. One student related that he liked using computers to access an online dating site. (The site he named is targeted to young adults). When asked about challenges with the use of computers, one student stated, "I don't go outside anymore." As far as the most productive use of the computers at the school, the students, teacher, principal, and Director of Education all agreed that being able to access more information online (rather than relying on the limited school library) was the most important benefit.

The Director shared that access to information on the internet had introduced a new problem in that the students liked to "cut and paste" information directly from the internet into their work, meaning that the teachers had to be vigilant in examining student work and had to educate them about the proper use of online resources. The Director indicated that students were "relying on their phones too much", sometimes during classes. As an example, he said students were using their phones in mathematics classes to find answers when they should have been solving problems themselves.

In terms of usage at the schools, the administrator said he was constantly installing firewalls to prevent students from using social media during school hours but that the students were always finding ways around these firewalls. The students were not supposed to use their phones at school to access the Internet, but, in fact, they were using them in this way. During the focus group, the students said that hearing notifications on their classmates' phones was distracting.

In summary, this school was the smallest of the schools visited. It is located in a community of 400 people and has five classrooms for children in elementary and high school. The school system lacked the benefits of economy of scale, making it difficult to purchase, and maintain, hardware and software. In this community, there was no onsite technical service available for the equipment due to its distance from the services it used in Quebec City, meaning that repairs and advice were difficult to obtain. The Director and principal spoke positively of the support they received through this service, but recognized the limitations from a service at a distance. The school's isolation from major centres posed challenges in providing professional development for teachers. While the Director was making every effort to find funds to purchase equipment, the lack of professional development with the new equipment meant that it was not always being used to its fullest potential. As indicated above, this school had reliable Internet access, and the participants were satisfied with their service. A major challenge identified by all participants was the lack of software in the Algonquin language, complicated by the existence of various dialects of the language.

\subsection{Nunavut}

The Internet within the school in Nunavut was limited as all Internet was via satellite and was controlled by the government of Nunavut. The territorial government has limited the use of Google mail, which prevented our use of the online survey. Substitution with the same questions in paper format was necessary. The lack of practical Internet access greatly reduced the amount of computer use for research or other activities that required the use of the Internet. A participant related that a simple email message could take up to 10 minutes to open. About four years prior to this study, a charitable foundation provided a set of laptops to the school, enough laptops for each child plus $10 \%$. The foundation also provided a two week training program on the software installed on the laptops to one teacher in the school. Over the course of the four year period, laptops required repair, with some becoming unusable.

Nunavut has a population of about 37,000 people spread over 1,900,000 square kilometres, with more than half of the communities having fewer than 1000 people. [7] The population density of Nunavut is the fifth lowest in the world at about 0.02 persons per square kilometer. In the 2013-2014 school year, a total of 9,728 students were enrolled in Kindergarten to Grade 12. [16]

Providing technical support, and repair and replacement of machines is extremely challenging in this environment. The Nunavut Department of Education has one technician who flies to each school in the territory during the school year. In the day or two assigned to each school during the year, 
the technician tries to make as many repairs as possible. The staff at the school reported that often the technician has to leave the school without all the work being completed and if a computer breaks down the day after he leaves, the school must wait a year for that machine to be serviced. The teacher who had been trained by the foundation was trying to repair computers if he could (although repair was not part of his training), but at the time of the visit, the school had only one class set of computers left. For this reason and others, the computers were used occasionally, perhaps once a week. Access to professional development for teachers and administrators was very limited in this school, as one might expect.

\subsection{Haudenosaunee (Iroquois) First Nation}

The Haudenosaunee (Iroquois) school was located in southern Ontario and was the largest of the communities we visited. It depended on satellite Internet, a finding that was unexpected as the community is near a mid-sized city. This community, however, suffered a similar lack of Internet speed as that found in Nunavut. One of the teachers indicated that when all the computers in the school were in use, the speed was slowed down so much that it was not possible to have the students follow along together with the lesson being taught. The students, teachers, and administrators all identified the slow speed of the Internet connection as a major challenge in trying to use ICT in the school.

The school lacked portable computers and relied on about 10 outdated stand alone computers that were not used on a regular basis. These computers were purchased in 1996. Because they were so dated, it was not possible to purchase software for them anymore. Even though the programs on the computers had been in use for a long time, one of the teachers stated that he believed that the software was not being used as effectively as it could because no professional development had been available for the teachers.

A concern expressed by one of the teachers was the limited access to computers that hampered their use either in class or for individual use. The other teacher said he used a SMARTboard in his classroom to create searches for information with the whole class, rather than having students search individually, to deal with the lack of access to computers and the slow speed when multiple machines were in use. For this reason, the speed of the internet seemed to be less concerning to this teacher. The first teacher stated that being able to purchase and use current software was something that she felt was critical for the use of ICT in the teaching and learning environment. A challenge mentioned by one of the teachers was keeping the students from accessing social media when using the computers on an individual basis. Perhaps due to the age of the computers, one of the teachers stated that when he would try to use the computers in the laboratory, there would always be one that was not working or co-operating, stating, "computers were made to make you angry." This statement demonstrates the frustrations the teachers were experiencing with their outdated computer laboratory.

The teachers and students named access to information as a main advantage of using computers in school. The teachers valued the ability to obtain information for planning lessons and the students valued it for completing assignments. The students, however, stated that they did not have much access to the computers at school, a situation that was confirmed by the teachers' and administrator's comments.

Other benefits of computers, named by the students, included instrumental uses, such as looking for a job, and skills development. One of the teachers believed that many of the students were "visual learners" and benefited from pictures and videos for information on new topics. Another benefit named by one of the teachers was the school Facebook page. On this page, teachers could post information for students and parents alike, such as information about class trips, assignments, and school events. One of the teachers said a benefit was that students could produce better quality work, meaning that their work was more visually pleasing.

When asked how they mainly used computers, the students indicated social media and search engines. One student said he wanted to try to create his own video games. Another student said he wanted to use various graphics and animation packages. When asked how a computer might be used at home, one student shared that he would be more motivated to learn the Indigenous language if he had a computer at home. One of the teachers said she wished that each student could have a personal iPad.

The school administrator reported that the main use of the computers was for the CAN-8 VirtuaLab program, which is used for language learning. The school was using content in this program developed by another Aboriginal community that uses the same language as the community under study. The other community received a grant to develop this content for instruction in the languages used by the Haudenosaunee peoples.

The administrator reported that the program could only be used in the school laboratory as the Internet service was so poor. The CAN-8 VirtuaLab program requires connection to the Internet. One of the teachers confirmed that the limited number of computers and the slow speed of the Internet made use of the language program difficult, but believed that having the online program was superior to having students use only library resources for language learning. 
The administrator expressed regret that the program could not be used more widely, including by community members. The administrator reported that teachers were accessing the language program through SMARTboards to allow whole class practice (as mentioned above), although the program was designed for individual use and practice. The administrator stated that the students in grades 7 and 8 were not meeting expectations for development and use in the Aboriginal language. She stated that, by that level, the students should be able to write a story in the language, but that none of the current students were able to do that. She implied that limited access to computers was hampering student progress in their language development. She did, however, state that the students were becoming computer literate because they were using the program so much.

The administrator related that the high school students did not have access to laptops, nor did they have access to a computer laboratory. The administrator indicated she was trying to get one computer into each classroom and that she wanted these students to have access to the $\mathrm{CAN}-8$ program as well. Because of limited access to the computers, the school had to be set up a schedule for the students to take the online tests associated with the CAN-8 program.

When asked what they would like to see in their schools, the teachers both indicated that more access to computers would be their priority. One teacher said if all the students had a personal iPad or similar device, he would use online or electronic textbooks. The other teacher wanted to be able to use more current software. As mentioned several times above, increased speed for Internet access was also desirable. Access to professional development was mentioned as something one teacher would like to have. The administrator said she was trying to secure the funds to purchase more computers, with her goal being to have one computer in each classroom, as indicated above.

In summary, the school would benefit from more accessible and faster Internet, more up to date computers, an infrastructure that supports ICT, and professional development for teachers.

\section{Conclusion}

There were different degrees of challenges among the schools including; access to Internet, lack of computers, supportive infrastructure, teacher use of ICT in teaching, professional development, available software, and student use of computers. Some challenges were common to those found in mainstream schools such as technical problems and off task behavior of students. The teachers and administrators identified barriers preventing the increased use of ICT, including the lack of professional development, resources, and Aboriginal language software. The administrators recognized there was a wide skill set range among teachers in the adoption of ICT integration into their teaching. Two communities only had access to Internet via satellite, which restricted the use of the Internet in the schools. Two communities had 'fast' Internet connections where the students' benefits included easier access to research through the Internet, facilitated organization through the use of Google drive, and the use of social media. The teachers desired more professional development in ICT integration, additional resources for ICT, and more development of Aboriginal language software.

\section{Acknowledgement}

The authors gratefully acknowledge the grant received from the Canadian Internet Registry Authority to support this research. We wish to thank the four Aboriginal communities that permitted us to conduct our research in their territories, and the administrators, teachers, and students who participated in this study.

\section{References}

[1] Baxter, P., \& Jack, S. (2008). Qualitative case study methodology: Study design and implementation for novice researchers. The Qualitative Report 13(4), 544-59.

[2] Creswell, J. W., \& Plano Clark, V. L. (2007). Designing and conducting mixed methods research. Thousand Oaks, CA: Sage Publications.

[3] European Schoolnet (2013). Survey of schools ICT in education: Benchmarking access, use and attitudes to technology in Europe's schools (2013). Luxembourg: Publications Office of the European Union.

[4] Galley, V., Gessner, S., Herbert, T., Thompson, K.T. \& Williams, L.W. (2016). Indigenous languages recognition, preservation and revitalization: A report on the National Dialogue Session on Indigenous Languages. First Peoples' Cultural Council. Retrieved from: http://www.fpcc.ca/files/ PDF/General/FPCC_National_Dialogue_Session_Report _Final.pdf. (Access date: 29 August, 2017).

[5] Gulek, J. C., \& Demrirtas, H. (2005). Learning with technology: The impact of laptop use on student achievement. Journal of Technology, Learning and Assessment 3(2), 4-38.

[6] Goldberg, A., Russell, M., \& Cook, A. (2003). The effect of computers on student writing: A meta-analysis of studies from 1992 to 2002. Journal of Technology, Learning, and Assessment, 2(1) 1-52.

[7] Government of Nunavut: Welcome to Nunavut: Nunavut Communities (2012). Retrieved from: http://www.gov.nu.ca/sites/default/files/files/FINAL\%20G N\%20Info\%20Packages\%20\%20Nunavut\%20Communitie s.pdf. (Access date: August 29, 2017). 
[8] Human Resources and Development Canada (2013). Indicators of Well-Being in Canada. Retrieved from: http://www4.hrsdc.gc.ca/.3ndic.1t.4r@-eng.jsp?iid=29 (Access date: 14 October 2013).

[9] Indigenous and Northern Affairs Canada (2016). First Nations. Retrieved from: https://www.aadncaandc.gc.ca/eng/1100100013791/1100100013795 (Access date: 29 August, 2017).

[10] ISTE NETS. (2009). Essential conditions. Retrieved from www.iste.org/docs/pdfs/netsessentialconditions (Access date: 15 October 2013).

[11] Kay, R. H. (2006). Evaluating strategies used to incorporate technology into preservice education: A review of the literature. Journal of Research on Technology in Education; 38(4), 383.

[12] Lagrange, J., Artigue, M., Laborde, C., \& Trouche, L. (2001). A meta study on IC Technologies in education: Towards a multidimensional framework to tackle their integration. In PME Conference (1), 1-111. Retrieved from http://didmat.dima.unige.it/miur/miur_dima/G/STORIA_D I_UNA_RICERCA/LAGRANGE.PDF (Access date: 26 October 2013).

[13] Laronde, G., MacLeod, K., \& Frost, L. (2017). A case study of the integration of information and communication technology in a Northern Ontario First Nation high school: Challenges and benefits. Journal of International Education Research, 13(1).

[14] Li, Q. \& Ma, X. (2010). A meta-analysis of the effects of computer technology on school students' mathematics learning. Educational Psychology Review. 22(3), 215-243.

[15] Nunavut Bureau of Statistics (2017). Population Estimates: Status Update Nunavut and Canada Population Estimates First Quarter, 2017. Retrieved from: http://stats.gov.nu.ca/en/Population\%20estimate.aspx (Access date: August 29, 2017).

[16] Nunavut Department of Education, Annual Report, 2013-2014. Retrieved from:

http://www.gov.nu.ca/sites/default/files/annual_report_201 3-2014_english_web.pdf (Access date: August 29, 2017).

[17] Statistics Canada (2011), Aboriginal Peoples in Canada: First Nations People, Métis and Inuit. Retrieved from: http://www12.statcan.gc.ca/nhs-enm/2011/as-sa/99011-x/99-011-x2011001-eng.cfm. (Access date: August 29, 2017).

[18] World Population Review, Nunavut Population 2017. Retrieved from: http://worldpopulationreview.com/ territories/nunavut-population/ (Access date: 29 August, 2017). 